\title{
COMPLICATED COURSE OF ISCHEMIC HEART DISEASE IN A PATIENT WITH OBSTRUCTIVE SLEEP APNEA
}

\author{
Eliska Sovova $^{\text {a* }}$, Milan Sova ${ }^{\mathrm{b}}$, Milada Hobzovac ${ }^{\mathrm{c}}$, Milan Kaminek ${ }^{\mathrm{d}}$, Vitezslav Kolek ${ }^{\mathrm{c}}$, \\ Milos Taborsky ${ }^{\mathrm{a}}$, Jiri Ostransky ${ }^{\mathrm{a}}$ \\ ${ }^{a} I^{\text {st }}$ Department of Internal Medicine, Faculty of Medicine and Dentistry, Palacky University Olomouc, Czech Republic \\ ${ }^{b}$ Faculty of Medicine and Dentistry, Palacky University Olomouc \\ c Department of Respiratory Medicine, Faculty of Medicine and Dentistry, Palacky University Olomouc \\ ${ }^{d}$ Department of Nuclear Medicine, Faculty of Medicine and Dentistry, Palacky University Olomouc \\ E-mail: eliska.sovova@seznam.cz
}

Received: November 1, 2010; Accepted with revision: February 10, 2011

Key words: Obstructive sleep apnea/Myocardial infarction/Complicated course/In stent restenosis

Background. Obstructive sleep apnea (OSA) can activate pathological routes which can lead to insulin resistance, development of atherosclerosis and hypertension. The combination of hypertension and OSA has an additive effect on the development of atherosclerosis. As a number of studies have revealed, that the incidence of OSA in patients with myocardial infarction is likely to be high.

Methods and results. We present a patient with acute myocardial infarction and no classical coronary artery disease risk factors: non-smoker, normal blood pressure, normal total and low-density lipoprotein cholesterol levels, borderline high-density lipoprotein cholesterol level, with good physical activity, no diabetes mellitus, no abdominal obesity, a negative family history. The only risk factor was untreated obstructive sleep apnea. The course of disease was complicated by subsequent in-stent restenosis and progression of atherosclerotic plaques, which led to the need for acute coronary artery bypass graft surgery complicated by consecutive in-anastomosis stenosis despite maximum cardiovascular therapy. One year of continuous positive airway pressure treatment was needed to stabilize his health condition, which is now stable for up to two years.

Conclusions. Given the complicated course of ischemic heart disease in patients with OSA, we believe that OSA diagnosis would be advisable each time these patients with symptoms of myocardial infarction, ischemic heart disease and OSA are examined. Even more important, however, is proper treatment of the OSA when it is present.

\section{INTRODUCTION}

The Sleep Heart Health Study (SHHS) has examined the cross sectional association between sleep-disordered breathing and self reported cardiovascular disease (CVD) and the multivariable-adjusted relative odds $(95 \% \mathrm{CI})$ of prevalent (self reported) CVD were $1.42(1.13-1.78)$ for the fourth quartiles ${ }^{1}$. Sleep-disordered breathing was associated more strongly with self reported heart failure (2.38), stroke (1.58), than with self reported CVD. The SHHS has shown, that in a group of patients free of self reported CVD in the begin of the study moderate levels of sleep-disordered breathing were common with a median Respiratory Disturbance Index (RDI) of 4.0. The risk for CVD events increased in future follow-up ${ }^{2}$. Mooe et al. ${ }^{3}$ concluded in the study of 408 patients with CVD, that sleep-disordered breathing is associated with a worse longterm prognosis and has an independent association with cerebrovascular events.

In a recent study Gottlieb et al. ${ }^{4}$ presented, that OSA was a significant predictor of incident coronary heart disease in men $\leq 70$ years of age. Among men 40-70 years old, those with $\mathrm{AHI} \geq 30$ were $68 \%$ more likely to develop coronary heart disease than those with AHI $<5$.

\section{CASE PRESENTATION}

A 54-year-old Caucasian man was admitted on $29^{\text {th }}$ March 2007 to the cardiology clinic due to serious chest pain. Vertebrogenic pain syndrome, hepatitis B in 1977 (he is HBsAg positive) and surgery for Achilles tendon were mentioned in the patient's medical history. $\mathrm{He}$ is a lifelong non-smoker. He was evaluated in a sleep laboratory several years ago where an obstructive sleep apnea was diagnosed. He was not treated or observed. Family history: mother died age 40 as a result of a rheumatic mitral valve disease; father died age 80 due to liver carcinoma; sister and children are healthy. Medication: silymarin.

Physical examination (PE): blood pressure (BP) $150 / 80$, heart rate (HR) 82 , weight $97 \mathrm{~kg}$, height $187 \mathrm{~cm}$, body mass index 27.7 and no other abnormalities.

Electrocardiogram: sinus rhythm, straightened ST I, II, V 5, 6, depression ST V 1-3.

Laboratory results: normal potassium, sodium, chlorides, alanine amino transferase, aspartate amino transferase, gamma glutamyl transferase, glycaemia, total cholesterol, high-density lipoprotein (HDL), triglycerides, low-density lipoprotein (LDL). Out of range: creatine kinase (CK) $3.57 \mu \mathrm{kat} / 1, \mathrm{CK} / \mathrm{CK} \mathrm{Mb} 14 \%$ (norm. $<6 \%$ ), troponin T $0.08 \mu \mathrm{g} / 1$ (norm. 0.03), bilirubin $38 \mu \mathrm{mol} / \mathrm{l}$. 
A coronarography was carried out and this revealed the following: occluded ramus diagonalis (RD1), 95\% ostial stenosis (RD2), 99\% critical stenosis ramus circumflexus (RCX) (Fig. 1), arteria coronaria dextra (ACD) without stenosis. Percutaneous coronary intervention (PCI]) was performed on RD1 with a stent coroflex $3.0 \mathrm{x}$ $13 \mathrm{~mm}$, (TIMI flow 3), PCI on RCX with a stent coroflex $3.0 \times 13 \mathrm{~mm}$ (a small residue of stenosis up to $15 \%$ ).

The patient was discharged in good health on $4^{\text {th }}$ April 2007. His medication included beta blocker (metoprolol), clopidogrel, aspirin, ACE inhibitor (ramipril), statin (atorvastatin), silymarin.

He was admitted to the respiratory clinic on $16^{\text {th }}$ April 2007 where he underwent a polysomnography. PE: BP, HR in normal range. Laboratory values were normal (ASTRUP, glycaemia, lipids). The Epworth sleepiness scale was 4. The polysomnography revealed 27.4 oxygen desaturations per hour, he spent $3.14 \%$ of sleep in oxygen saturation less then $90 \% \mathrm{SaO}_{2}$, apnea-hypopnea index (AHI) $30.45 . \mathrm{He}$ did not meet the criteria for continuous positive airway pressure (CPAP) treatment set by the health insurance company. He was scheduled for reevaluation.

A follow-up polysomnography took place on $28^{\text {th }}$ May 2007 and revealed 27.0 oxygen desaturation per h, $11 \%$ of the time in the oxygen saturation less then $90 \% \mathrm{SaO}_{2}, \mathrm{AHI}$ 30. A request for a CPAP device for the health insurance company was filled out.

An echocardiographic examination was performed on $31^{\text {st }}$ May 2007. It revealed hypokinesis of the lateral wall and the worsening of ejection fraction (EF) to $40 \%$.

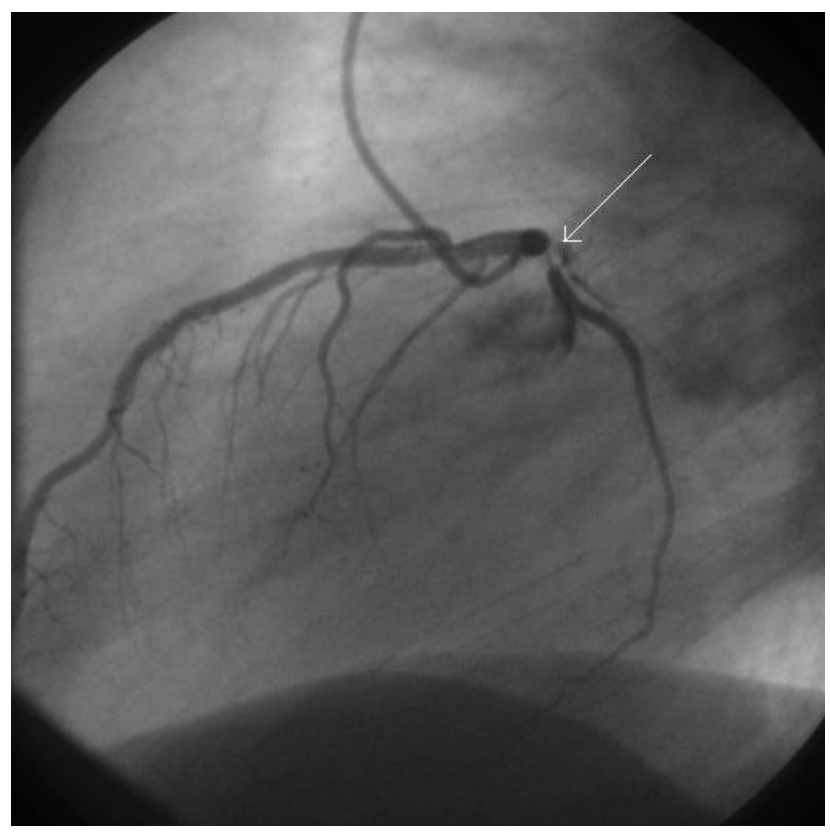

Fig. 1. Coronarography, $99 \%$ critical stenosis ramus circumflexus.

The patient underwent single-photon-emission computed tomography (SPECT) on June 2007 which showed hypokinesis laterally and inferoapically, the resting EF was $45 \%$, the defect was reversible and assessed as medially severe ischemia (Fig. 2).

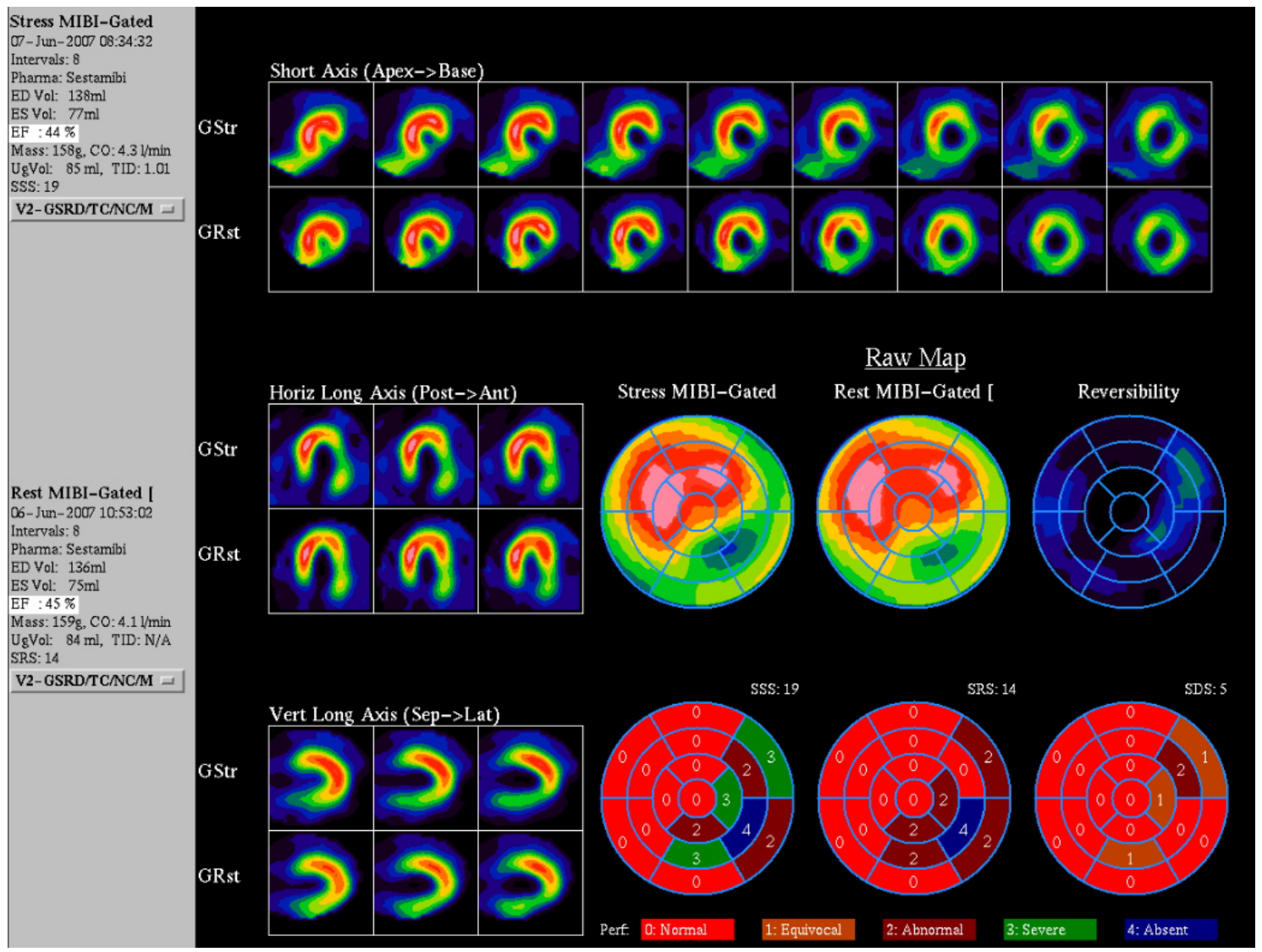

Fig. 2. SPECT. Hypokinesis laterally and inferoapically, the reversible defect (medially severe ischemia). 


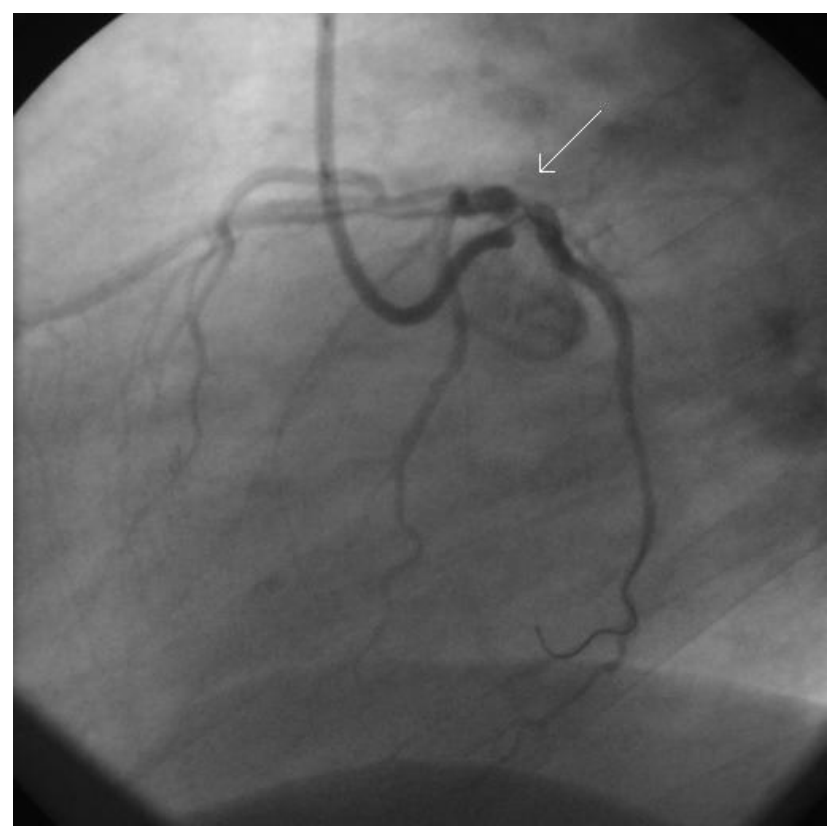

Fig. 3. Coronarography, in stent restenosis $90 \%$ of ramus circumflexus.

A control hospitalization at the cardiology department took place on $12^{\text {th }}$ June 2007 , PE values at admission were: BP 130/90, HR 76, laboratory values were within normal levels, total cholesterol $2.44 \mathrm{mmol} / 1$, triglycerides $1.56 \mathrm{mmol} / 1$, HDL $0.98 \mathrm{mmol} / 1$, LDL $0.76 \mathrm{mmol} / 1$. The patient subsequently underwent a coronarography, where in stent restenosis $90 \%$ of RD1, stenosis $90 \%$ of RD2, in stent restenosis $90 \%$ of RCX were found (Fig. 3). All of these findings were managed by a balloon angioplasty. The patient was discharged on $15^{\text {th }}$ June 2007 with the following medication: carvedilol, ramipril, atorvastatin, clopidogrel, aspirin, trimetazidine.

The patient was provided with a CPAP device on $23^{\text {rd }}$ June 2007 with the pressure set at $5.5 \mathrm{~cm} \mathrm{H}_{2} \mathrm{O}$.

The patient was hospitalized at the respiratory clinic after 1 month of CPAP treatment on the $6^{\text {th }}$ September 2007. The time of usage for the CPAP was $330 \mathrm{~h}$, with the polysomnography showing the following: 6.2 desaturations, almost $0 \%$ of sleep in saturation under $90 \% \mathrm{SaO}_{2}$, AHI 13.2. The pressure was adjusted to $6.5 \mathrm{~cm} \mathrm{H}_{2} \mathrm{O}$ due to this result.

A SPECT was carried out due to chest pain on the $16^{\text {th }}$ October 2007. Resting perfusis: defect of perfusis laterally and inferoapically, quantitative perfusive abnormality in a range of $25 \%$ out of the left ventricle, $\mathrm{SSS}=15$. Gated SPECT: Hypokinesis laterally and inferoapically, resting EF $47 \%$. Defect of the resting perfusis laterally and inferoapically which was consistent with the previous examination on June 2007 (before PCI).

A patient was brought in by ambulance due to chest pain on the $19^{\text {th }}$ October 2007. PE: BP, HR in normal range. With regard to difficulties and SPECT findings, the patient re-underwent a coronarography, where $50 \%$ stenosis of trunk, $90 \%$ stenosis of proximal ramus interventricularis anterior (RIA), 20\% in-stent stenosis of RD1 and 90\% ostial stenosis were found. The patient was indicated for surgical treatment (due to $90 \%$ stenosis of proximal RIA).

The patient underwent acute surgery on the $21^{\text {st }}$ October 2007 as coronary artery bypass (RIA-IMA, RCX+RDI seq) with no post operative complications.

The patient was admitted to hospital because of chest pain on the $3^{\text {rd }}$ January 2008. Coronarography was carried out with a finding of critical stenosis of bypass anastomosis to RMS-managed by PCI with implantation of coated stent-DES Cypher select 2.5 x $8 \mathrm{~mm}$, after discharge without complications.

Hospitalization at the respiratory clinic took place on the $21^{\text {st }}$ July 2008. The duration of CPAP use was 1870 h. A polysomnography showed the following: 2 desaturations, $0 \%$ of sleep in saturation under $90 \% \mathrm{SaO}_{2}, \mathrm{AHI}$ 8. The pressure was adjusted to $8 \mathrm{~cm} \mathrm{H}_{2} \mathrm{O}$ and patient received a facial mask because of the result.

The patient has not reported any significant complaint after this hospitalization. He has remained on the same pharmacological therapy till now (last visit November 2010).

\section{DISCUSSION}

We present a patient with an acute myocardial infarction who was without any classic coronary artery disease risk factors [non-smoker, normal blood pressure, normal total and low-density lipoprotein cholesterol levels, borderline high-density lipoprotein cholesterol level, with good physical activity, without diabetes, without abdominal obesity, a negative family history]. The only risk factor which was present in the patient was untreated OSA.

As a number of studies have revealed that the incidence of OSA in patients with myocardial infarction (MI) is likely to be high. Lee et al. ${ }^{5}$ found that in a group of 120 patients with acute MI, 65,7\% has OSA with AHI>15. In these patients diabetes mellitus was a risk factor for OSA (OR 2.86).

OSA can also figure as a risk factor for MI. The diurnal variation of progression is different in patients with or without OSA. Kuniyoshi et al. ${ }^{6}$ reported that in patients with an onset of MI from midnight to 6 am, up to $91 \%$ of patients had OSA and the risk of developing MI was six times higher than during the rest of the day. Difficulties also occurred in our patients around $3 \mathrm{am}$.

OSA can activate pathological routes which can lead to insulin resistance, development of atherosclerosis and hypertension ${ }^{7}$. The combination of hypertension and OSA has an additive effect on the development of atherosclerosis. The Intima-media index has a positive correlation with the systolic blood pressure and the AHI index ${ }^{8}$. Systemic inflammation, sympathetic activation, the effect of high blood pressure and oxidative stress, can all lead to the development of the endothelial dysfunction in patients with OSA ${ }^{9}$.

Endothelial dysfunction leads to an increase in the risk of cardiovascular disease, a decrease in endothelial NO and increase in oxidative stress in patients with $\mathrm{OSA}^{10}$. Certain cytokines (e.g. TNF- $\alpha$ ) can participate in the 
development of the endothelial dysfunction ${ }^{11}$. Although classical risk factors were absent in the case of the patient described, the findings of advanced atherosclerosis were substantial, with significant progressions in the period without adequate treatment for OSA.

A potential mechanism for the development of acute MI in our patient could have been higher trombocyte agregability of thrombocytes, which has been described in patients with $\mathrm{OSA}^{12}$.

The clinical status of our patient had not been stabilized over maximal cardiological treatment until one year of adequate use of CPAP. The improved prognosis of patients with heart disease after CPAP treatment has been described by several authors.

Buchner et al. ${ }^{13}$ for example, showed that CPAP treatment of patients with OSA had reduced risk of cardiovascular event (non-fatal MI, acute coronary syndrome with revascularization, death because of MI ) by $64 \%$ in a group of 449 patients independent of age and coincident co-morbidities. In a similar fashion, Marin et al. ${ }^{14}$ described an increase in fatal events (OD 2.87) and nonfatal events in patients with untreated OSA. In the same manner, Doherty et al. ${ }^{15}$ have confirmed reduced cardiovascular mortality in patients with treated OSA in comparison with the control group. CPAP treatment leads to a decrease in thrombocyte activation and this may explain the stabilization of the health status of our patient following long-term use of the CPAP device ${ }^{16}$.

Cassar et al. ${ }^{17}$ showed that patients with OSA who are treated with CPAP have a lower incidence of post PCI cardiac death in comparison with patients without treatment.

One year of continuous positive airway pressure treatment was needed to stabilize health condition of our patient, which is now stable for up two years.

\section{CONCLUSION}

Given the complicated course of ischemic heart disease in patients with OSA, we believe that OSA diagnosis would be advisable each time these patients with symptoms of myocardial infarction, ischemic heart disease and OSA are examined. Even more important, however, is proper treatment of the OSA when it is present.

\section{REFERENCES}

1. Shahar E, Whitney CW, Renine S, Lee ET, Newman AB, Nieto FJ, O'Connor GT, Boland LL, Schwartz JE, Samet JM. Sleep disordered breathing and cardiovascular disease. Cross sectional results of the Sleep Heart Health Study. Am J Respir Crit Care Med 2001;163(1):19-25.

2. Newman AB, Nieto FJ, Guidry U, Lind BK, Redline S, Pickering TG, Quan SF. Relation of sleep- disordered breathing to cardio- vascular disease risk factors: the Sleep Heart Health Study. Am J Epidemiol 2001;154(1):50-9.

3. Mooe T, Franklin KA, Holmstrom K, Rabben T, Wiklund U. Sleepdisordered breathing and coronary artery disease. Am J Respir Care Med 2001;164(10):1910-1913.

4. Gottlieb DJ, Yenokyan G, Newmann AB, O ' Connor GT, Punjabi NM, Quan SF, Redline S, Resnick HE, Tong EK, Diener-West M, Shahar E. Prospective study of obstructive sleep apnea and incident coronary heart disease and heart failure. The Sleep Heart Health Study. Circulation 2010;122:352-360.

5. Lee CH, Khoo SM, Tai BC, Chong EY, Lau C, Than Y, Shi DX, Lee LC, Kailasam A, Low AF, Teo SG, Tan HC. Obstructive sleep apnea in patients admitted for acute myocardial infarction. Prevalence, predictors, and effect on microvascular perfusion. Chest 2009;135(6):1488-95.

6. Kuniyoshi FH, Garcia-Touchard A, Gami AS, Romero-Corral A, van der Walt C, Pusalavidyasagar S, Kara T, Caples SM, Pressman GS, Vasquez EC, Lopez-Jimenez F, Somers VK. Day night variation of acute myocardial infarction in obstructive sleep apnea. J Am Coll Cardiol 2008;52(5):343-6.

7. Pack AI, Gislason T. Obstructive sleep apnea and cardiovascular disease: a perspective and future directions. Prog Cardiovasc Dis 2009;51(5):434-51.

8. Sin DD, Fitzgerald F, Parker JD, Newton G, Floras JS, Bradley TD. Risk factors for central and obstructive sleep apnea in 450 men and women with congestive heart failure. Am J Respir Crit Care Med 1999; 160:1101-1106.

9. Somers VK, White DP, Amin R, Abraham WT, Costa F, Culebras A, Daniels S, Floras JS, Hunt CE, Olson LJ, Pickering TG, Russell R, Woo M, Young T. Sleep apnea and cardiovascular disease: An American Heart Association/American College of Cardiology Foundation Scientific Statement from the American Heart Association Council for High Blood Pressure Research Professional Education Committee, Council on Clinical Cardiology, Stroke Council, and Council on Cardiovascular Nursing In Collaboration With the National Heart, Lung, and Blood Institute National Center on Sleep Disorders Research (National Institute of Health). J Am Coll Cardiol 2008;52:686-717.

10. Jelic S, Le Jemtel TH. Inflammation, oxidative stress, and the vascular endothelium in obstructive sleep apnea. Trends Cardiovasc Med 2008;18(7):253-60.

11. Lavie L, Polotsky V. Cardiovascular aspects in obstructive sleep apnea syndrome- molecular issues, hypoxia and cytokine profiles. Respiration 2009;78(4):361-370.

12. Cox D, Bradford A. Continuous positive airway pressure and platelet activation in obstructive sleep apnoea. Respiration 2009;77:1820.

13. Buchner NJ, Sanner BM, Borgel J, Rump LC. Continuous positive airway pressure treatment of mild to moderate obstructive sleep apnea reduces cardiovascular risk. Am J Respir Crit Care Med 2007;176(12):1274-80.

14. Marin JM, Carrizo SJ, Vincente E, Agusti AGN. Long term cardiovascular outcomes in men with obstructive sleep apnoea-hypopnoea with or without treatment with continuous positive airway pressure: an observational study. Lancet 2005;365:1046-1053.

15. Doherty LS, Kiely JL, Swan V, McNicolas WT. Long term effects of nasal continuous positive airway pressure therapy on cardiovascular outcomes in sleep apnea. Chest 2005;127(6):2076-2084.

16. Akinnusi ME, Paasch LL, Szarpa KR, Wallace PK, El Solh AA. Impact of nasal continuous positive airway pressure therapy on markers of platelet activation in patients with obstructive sleep apnea. Respiration 2009;77:25-31.

17. Cassar A, Morgenthaler T, Lennon R, Rihal CS, Lerman A. Treatment of obstructive sleep apnea is associated with decreased cardiac death after percutaneous coronary intervention. Journal of the American College of Cardiology 2007;50(14):1310-1314. 